\title{
Inequalities in health-related quality of life and the contribution from socioeconomic status: evidence from Tibet, China
}

\author{
JieAnNaMu ${ }^{1+}$, Xinpeng $\mathrm{Xu}^{1+}, \mathrm{Hua}_{\mathrm{You}}{ }^{2^{*}}, \mathrm{Hai}_{\mathrm{Gu}}{ }^{1 *}$, Jinghong $\mathrm{Gu}^{3}$, Xiaolu $\mathrm{Li}^{4}$, Nan Cui ${ }^{1}$ and Yun Kou ${ }^{1}$
}

\begin{abstract}
Background: This study aimed to understand the association between socioeconomic status (SES) and Health Related Quality of Life (HRQOL) and the contribution of SES to health inequality among Tibetans of agricultural and pastoral areas (APA) in Tibet, China.

Methods: The data were from Health Survey of Tibetans in APA conducted in 2014. A total of 816 respondents were enrolled for the analysis Multiple linear regression was employed to examine the relationship between SES and HRQoL. Concentration index (Cl) was used to measure the degree of health inequality and a Wagstaff-type $\mathrm{Cl}$ decomposition method was applied to measure the contribution of SES to inequality.

Results: SES had significant association with HRQoL among the Tibetans in APA. The high SES group was more likely to have a higher Eq-5d index (0.77 vs. $0.67, P<0.001)$ and VAS (72.94 vs. $62.41, P<0.001)$ than the low SES group. The Concentration index of the Eq-5d index and VAS for total sample was 0.022 and 0.026 respectively, indicating a slight pro-rich inequality among this population. The decomposition analyses showed the SES is the main contributor to health inequality and contributed 45.50 and $41.39 \%$ to inequality for the Eq-5d index and VAS, respectively.

Conclusion: The results showed SES is positively associated with HRQoL among Tibetans in APA. There was a slight pro-rich inequality in the health of the participants and most health inequality was attributable to SES. This study is helpful in gaining an insight into the HRQOL, health inequality and the relationship between SES and health inequality among Tibetans of APA in China.
\end{abstract}

Keywords: Socioeconomic status, Health related quality of life, Health inequality, Tibet, China

\section{Background}

This study investigated Tibetans living in agricultural and pastoral areas (APA) in Tibet, China. Tibet is located on the Qinghai-Tibet plateau in southwest China, and its social and economic development level ranks

\footnotetext{
*Correspondence: youhua@njmu.edu.cn; ghai1008@nju.edu.cn

${ }^{\dagger} J i e A n N a M u$ and Xinpeng Xu contributed equally to this work.

2Department of Social Medicine and Health Education, School of Public Health, Nanjing Medical University, Nanjing, China

${ }^{1}$ Center for Health Policy and Management Studies, Nanjing University, Nanjing, China

Full list of author information is available at the end of the article
}

relatively low in China's provinces [1]. Most of the population in Tibet is comprised of farmers and herders, who are scattered in remote rural areas. The education level of the population there is relatively low, and their limited source of income mainly depends on agricultural production [2]. In addition, the health risks faced by the population in this area are higher than those in lowaltitude areas. Tibetan of APA living in high-altitude areas are faced with poor transportation and communication conditions, and low access to medical services [3]. Some particularities that make the investigation difficult

(c) The Author(s). 2020 Open Access This article is licensed under a Creative Commons Attribution 4.0 International License, which permits use, sharing, adaptation, distribution and reproduction in any medium or format, as long as you give appropriate credit to the original author(s) and the source, provide a link to the Creative Commons licence, and indicate if changes were made. The images or other third party material in this article are included in the article's Creative Commons licence, unless indicated otherwise in a credit line to the material. If material is not included in the article's Creative Commons licence and your intended use is not permitted by statutory regulation or exceeds the permitted use, you will need to obtain permission directly from the copyright holder. To view a copy of this licence, visit http://creativecommons.org/licenses/by/4.0/ The Creative Commons Public Domain Dedication waiver (http://creativecommons.org/publicdomain/zero/1.0/) applies to the data made available in this article, unless otherwise stated in a credit line to the data. 
in this group include factors such as region, ethnicity, and lifestyle. Therefore, there is a lack of previous literature on the health status and quality of life of this population. Studies investigating the relationship between socioeconomic status and health status among this population are scarce as well.

Socioeconomic status (SES) which commonly measured by education, income and occupation is an overall measure of the economic and social status of individuals or families relative to others [4]. It has generally been associated with differences in health. A large number of literatures examining the relationship and its stabilization between SES and health [5]. Most studies have agreed that socioeconomic status was the most important determinant of an individual's health [6-8], since it can affect individual health through a variety of mechanisms. People with low SES are more likely to have unhealthy habits and face higher socio-economic pressure, and SES is also closely correlated with the quantity and quality of health care services available. Despite differences in circumstances and approaches to measuring and analyzing, studies have consistently displayed that people with low SES were more likely to have worse health status $[6,9,10]$. Arguably the same patterns ought to be found in a homogeneous group such as the Tibetans in APA.

On the other hand, the relationship between SES and Health inequality have been discussed extensively, which has achieved a series of important results [7, 11-13]. The monographs of Marmot and Wilkinson (2005), and Bartley (2016) consistently showed that socioeconomic status plays an important role in health and health inequality. Some empirical studies supported similar conclusions. Previous studies have used education and income to measure SES, and discussed its relationship with health inequality [14]. Mackenbach et al. (2008) found that there were differences in the level of health inequality associated with socioeconomic status of European countries [13]. Studies have shown that health inequalities are widespread in many countries, and social class differences in mortality are increasing [13]. Also widening income inequality would do harm to people's health status [15], and reduced income inequality offered better population health [16]. Analogously, Singh's research in India found that income and education were the main contributors to health inequality [17]. However, it is not clear whether the conclusions previously reached about health inequality and its determinants in general are consistent in Tibetans of APA.

Health-related quality of life (HRQoL) is an important indicator to measure health status comprehensively and is increasingly used to measure the health inequality among different social groups [18]. As it is directly or indirectly related to a variety of diseases, SES is also regarded as an important factor in determining an individual's quality of life [19]. In the past decade, SES and its relationship with quality of life has become an important research direction in the field of health care. There are some studies focusing on the correlation between SES and HRQoL, and similar conclusions with the relationship between SES and health are drawn. Low SES is associated with poor HRQoL, even after other confounding factors are adjusted [20-22]. This study performed a population-based study to measure the HRQoL and inequality of the residents in the agricultural and pastoral areas of Tibet, and to understand the correlation between SES and HRQoL in this population.

\section{Methods}

\section{Data and sampling}

The data used in this study were derived from Health Survey of Tibetans in APA conducted in 2014. The survey aimed to study the health status and its influencing factors among Tibetans in APA. Some local grass-root health workers were recruited as investigators and attended at the trainings conducted by researchers from Nanjing University and Nanjing Medical University. Of the more than three million people in the Tibet autonomous region, more than 2.5 million are farmers and herders. The survey adopted a multi-stage stratified random sampling strategy based on altitude, infrastructure, and social and economic development. First, counties were randomly selected from seven regions in Tibet (i.e., Lhasa, Nyingchi, Shannan, Xigaze, Qamdo, Naqu, Ali). Second, the administrative villages in each county were randomly selected. Finally, 10 to 12 households were randomly drawn from each village. A total of 308 households comprising 850 individuals from 28 villages in 14 counties were chosen to participate in the survey (Fig. 1).

Participants with missing values on key variables were removed from the sample (34 questionnaires were excluded, accounting for 4\%), and a total of 816 valid responses were included in the analysis sample, accounting for $96 \%$.

\section{Measurement of HRQoL}

Eq-5d-3 L was employed to measure the HRQoL of respondents. The equivalence between the Chinese and English version of this scale has been proven [23]. Several studies have also demonstrated its reliability and validity $[24,25]$. The scale consists of two parts: a fivedimensional questionnaire and a Visual Analog Scale (VAS). The questionnaire includes mobility, self-care, usual activities, pain/discomfort, and anxiety/depression. Each dimension contains three response levels $(1=$ no problems, $2=$ some/moderate problems, and $3=$ extreme problems). The questionnaire could measure 243 possible combinations of health conditions. We employed 
Tibet Province

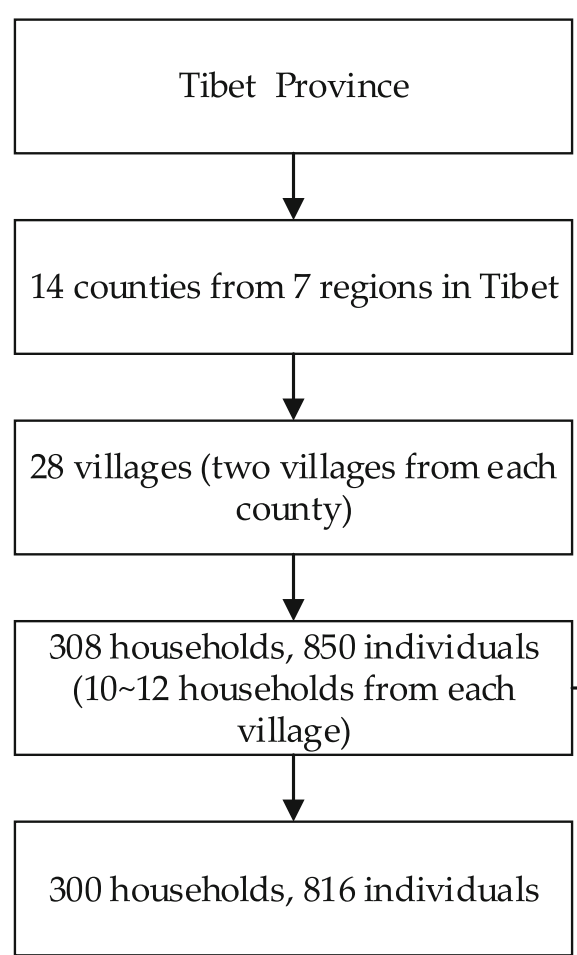

8 households, 34 individuals removed for missing data

Fig. 1 Flow diagram of survey

the Japan Time-Trade Off (TTO) to convert the five dimensions into an index ranging from -0.11 to 1.00 [26]. TTO is a widely-used method to convert responses to the EQ. 5D scale into specific HRQoL index. The VAS is a standard $0-100$ vertical visual analogue scale (like a thermometer from 0 to 100) in order to record an individual's rating for his/her HRQoL [27]. A respondent having a higher index or VAS score is healthier than others. The Cronbach's $\alpha$ of Eq-5d index was 0.867.

\section{Measurement of socioeconomic status (SES)}

Education, income, and housing conditions were used to define the SES variables. Several studies have used variables such as education, income, and occupation to represent individuals' socioeconomic status $[4,6,8,28-30]$. However, there is no difference in occupation since the subjects of our study are farmers in agricultural and pastoral areas. We added housing conditions as one of the main bases for SES classification within the population. The housing conditions used in this study are mainly based on the housing materials and housing facilities of the respondents, including the main source of cooking fuel, type of drink water, toilet facilities, and type of accommodation. The responses are dichotomized as reporting any poor living conditions versus none of the poor conditions. All respondents were asked to report their education level, which was divided into two categories, including illiterate, elementary and above. Given the possible effects of economic scale on household income, we employed the equivalized per capita income (eqpcinc) to represent individual economic condition [31-33]. The calculation formula of eqpcinc is as following Eq. (1), in which household income represents the annual actual household income, and family size is the actual number of family members.

$$
\text { eqpinc }=\frac{\text { household income }}{(\text { family size })^{0.56}}
$$

We generated the dummy income-based group variable based on the median of eqpcinc, representing whether the respondent is relatively wealthy or poor. In addition, poor housing conditions was used as another indicator of socioeconomic status.

We define the SES as a dummy variable. When SES is equal to zero, it indicated individuals classes as illiterate, in the low-income group, and with poor housing conditions. SES is equal to 1 under other values of these three variables, representing high socioeconomic status.

\section{Covariates}

Previous studies have shown that factors associated with HRQoL include individual characteristics, health-related behaviors, access to medical care, chronic disease [34-36]. Accordingly, this study contains these four types of covariates to be taken as confounders. The first category describes individual demographic characteristics, including 
age, gender, and marital status. The second category describes health-related behaviors, including smoking (the respondent has ever smoked or is a smoker now), brush teeth every day (whether the respondent brushes his or her teeth every day), and medical examination (whether the respondent participated in medical examinations during the last year). The third category was distance (whether the respondent lives at least $3 \mathrm{~km}$ from the nearest medical facility), representing the access to medical care. The fourth category was chronic disease (whether the respondent has been diagnosed with any chronic disease).

\section{Statistical analysis}

Multiple linear regressions were employed to examine the relationship between SES and HRQoL. The dependent variables included the Eq-5d index and VAS. SES was the core independent variable in regression models.

The concentration index $(\mathrm{CI})$ is widely used to measure health inequalities associated with socioeconomic status [32, 33, 37, 38]. The CI is defined as twice the area between the concentration curve and the line of equality. In our study, heath inequality was calculated as follows:

$$
C I=\frac{2}{n \cdot \mu} \sum_{i=1}^{n} H R Q o L_{i} R_{i}-1
$$

Where $H R Q o L_{i}$ is the Eq-5d index or VAS score of the $i^{\text {th }}$ individual, $n$ is the number of observations, $\mu$ is the average of Eq-5d index or VAS. $R_{i}$ is the $i^{\text {th }}$ individual's rank in terms of eqpcinc. The range of $\mathrm{CI}$ is $[-1,1]$. When $\mathrm{CI}$ is 0 , the concentration curve is an equality line of 45 degrees, and there is no inequality. When $\mathrm{CI}$ is positive, the concentration curve is below the equality line, indicating the existence of pro-rich inequality. When CI is negative, the concentration curve is above the equality line, indicating the existence of pro-poor inequality. A higher absolute CI means a higher level of health inequality. This study adopted a Wagstaff-type CI decomposition method to analyze the contributions of different factors to health inequality [39]. The calculation process is as follows:

First, the following linear regression model is established:

$$
H R Q o L_{i}=\alpha+\sum_{k} \beta_{k} x_{k i}+\varepsilon_{i}
$$

Where $\alpha$ represents the intercept, $x_{1}, \cdots, x_{k}$ represent the $k$ independent variables, $\beta_{1}, \cdots, \beta_{k}$ represent the corresponding coefficients, and $\varepsilon_{i}$ represents the error term.

Secondly, the CI of HRQoL can be rewritten based on the above model as follows:

$$
C I=\sum_{k}\left(\beta_{k} \tilde{x}_{k} / \mu\right) C_{k}+G C_{\varepsilon} / \mu
$$

where $\tilde{x}_{k}$ represents the means of the $k^{\text {th }}$ independent variable, $G C_{\varepsilon}=\frac{2}{n} \sum_{i=1}^{n} \varepsilon_{i} R_{i}, C_{k}$ represents the CI of the $k^{\text {th }}$ variable based on the same calculation formula of $\mathrm{CI}$ (Eq.(1)) for HRQoL. Eq. (3) indicates that the CI of HRQoL consists of deterministic and residual components. $\left(\beta_{k} \tilde{x}_{k} / \mu\right) C_{k}$ is the contribution of the $k^{\text {th }}$ determinant of health inequality, and the contribution rate is $\frac{\left(\beta_{k} \tilde{x}_{k} / \mu\right) C_{k}}{C I} \times 100 \%$.

The Stata 15.1 (StataCorp., College station, Texas) were used for data analysis in the study.

\section{Results}

\section{Characteristics of the study population}

Table 1 describes the basic characteristics of the study population. The average age of the respondents was 38.74 years $(\mathrm{SD}=18.82)$, $426(52.21 \%)$ were female, and $33.7 \%$ were not married. For socioeconomic variables, $62.87 \%$ were illiterate, $66.67 \%$ had poor housing conditions, and the annual equivalized per capita income was 71,500 Yuan (10,600 dollars). A total of $40.07 \%$ of the respondents lived on less than $\$ 1.90$ a day, which has been suggested as the international poverty line by the World Bank [40, 41]. The average score of Eq-5d index and VAS was 0.74 and 69.9 , respectively.

\section{HRQoL among different SES groups}

Table 2 described the average Eq-5d scores of different groups in the total sample and gender samples. For the total sample, the high SES group was more likely to have a higher Eq-5d index $(0.77$ vs. $0.67, P<0.001)$ and VAS (72.94 vs. $62.41, P<0.001$ ) than the low SES group. Specifically, the individuals with formal education, relatively higher income, and non-poor housing conditions were more likely to have higher Eq-5d index and VAS than their corresponding comparison groups. The results of Eq-5d index and VAS for different SES variables are similar in gender subsamples.

\section{The relationship between SES and HRQoL}

The results of multiple linear regression showed that SES was significantly associated with Eq-5d index (Table 3)/ VAS (Table 4). For the total sample, the low SES group has a lower Eq-5d index $(P=0.002)$ and VAS $(P=0.002)$ than others. For females and males, the results of the association between SES and the Eq-5d were similar for the index $(P=0.02, P=0.035)$ and VAS $(P=0.03, P=0.03)$.

\section{Health inequality and its decomposition}

Table 5 shows the CI of Eq-5d index/VAS in different groups. For the total sample, the CI of the Eq-5d index and VAS were 0.022 and 0.026 , while they were 0.023 and 
Table 1 Description of variables $(N=816)$

\begin{tabular}{|c|c|c|c|c|c|c|}
\hline \multirow[t]{2}{*}{ Variables } & \multicolumn{2}{|c|}{ Total sample $(N=816)$} & \multicolumn{2}{|c|}{ Female $(N=426)$} & \multicolumn{2}{|c|}{ Male $(N=390)$} \\
\hline & $\mathrm{N} /$ mean & $\% / S D$ & $\mathrm{~N} /$ mean & $\% / S D$ & $\mathrm{~N} /$ mean & $\% / S D$ \\
\hline Age & 38.74 & 18.82 & 38.89 & 18.97 & 38.57 & 18.68 \\
\hline \multicolumn{7}{|l|}{ Gender } \\
\hline Female & 426 & 52.21 & & & & \\
\hline Male & 390 & 47.79 & & & & \\
\hline \multicolumn{7}{|l|}{ Marital Status } \\
\hline Unmarried & 275 & 33.70 & 143 & 33.57 & 132 & 33.85 \\
\hline Married & 541 & 66.30 & 283 & 66.43 & 258 & 66.15 \\
\hline \multicolumn{7}{|l|}{ Smoking } \\
\hline No & 364 & 44.61 & 214 & 50.23 & 150 & 38.46 \\
\hline Yes & 452 & 55.39 & 212 & 49.77 & 240 & 61.54 \\
\hline \multicolumn{7}{|l|}{ Brush teeth every day } \\
\hline No & 570 & 69.85 & 290 & 68.08 & 280 & 71.79 \\
\hline Yes & 246 & 30.15 & 136 & 31.92 & 110 & 28.21 \\
\hline \multicolumn{7}{|l|}{ Medical examination } \\
\hline No & 588 & 72.06 & 302 & 70.89 & 286 & 73.33 \\
\hline Yes & 228 & 27.94 & 124 & 29.11 & 104 & 26.67 \\
\hline \multicolumn{7}{|l|}{ Distance } \\
\hline Within three kilometers & 322 & 39.46 & 179 & 42.02 & 143 & 36.67 \\
\hline Three kilometres away & 494 & 60.54 & 247 & 57.98 & 247 & 63.33 \\
\hline \multicolumn{7}{|l|}{ Chronic diseases } \\
\hline Without & 590 & 72.30 & 305 & 71.60 & 285 & 73.08 \\
\hline With & 226 & 27.70 & 121 & 28.40 & 105 & 26.92 \\
\hline \multicolumn{7}{|l|}{ Socioeconomic Status } \\
\hline Low & 236 & 28.92 & 138 & 32.39 & 98 & 25.13 \\
\hline High & 580 & 71.08 & 288 & 67.61 & 292 & 74.87 \\
\hline \multicolumn{7}{|l|}{ Educational Level } \\
\hline Illiteracy & 513 & 62.87 & 298 & 69.95 & 215 & 55.13 \\
\hline Elementary and above & 303 & 37.13 & 128 & 30.05 & 175 & 44.87 \\
\hline \multicolumn{7}{|l|}{ Poor housing conditions } \\
\hline Yes & 544 & 66.67 & 297 & 69.72 & 247 & 63.33 \\
\hline No & 272 & 33.33 & 129 & 30.28 & 143 & 36.67 \\
\hline Eqpcinc (thousand Yuan) & 7.15 & 8.62 & 6.88 & 8.47 & 7.44 & 8.78 \\
\hline \multicolumn{7}{|l|}{ Income-based group } \\
\hline Quintile1 (poor) & 408 & 50.00 & 218 & 51.17 & 190 & 48.72 \\
\hline Quintile2 (rich) & 408 & 50.00 & 208 & 48.83 & 200 & 51.28 \\
\hline \multicolumn{7}{|c|}{ Below the international poverty line ${ }^{a}$} \\
\hline No & 489 & 59.93 & 252 & 59.15 & 237 & 60.77 \\
\hline Yes & 327 & 40.07 & 174 & 40.85 & 153 & 39.23 \\
\hline Eq-5d index & 0.74 & 0.18 & 0.73 & 0.18 & 0.75 & 0.18 \\
\hline VAS & 69.90 & 19.33 & 69.02 & 18.95 & 70.86 & 19.72 \\
\hline
\end{tabular}

${ }^{a}$ The variable is defined if the per capita income of an individual is below the international poverty line ( $\$ 1.9$ a day). Since the 2011 PPPs for Rural China is 3.04 , the international poverty line for China rural residents is $1.9 * 3.04 * 365=2108.24$ Yuan. If the per capita income of an individual was less than 2108.24 Yuan, the individual lived below the international poverty line 
Table 2 The HRQoL among different population group

\begin{tabular}{|c|c|c|c|c|c|c|c|c|}
\hline \multirow[t]{3}{*}{ Variables } & \multicolumn{4}{|c|}{ Total sample $(N=816)$} & \multicolumn{2}{|c|}{ Female $(N=426)$} & \multicolumn{2}{|c|}{ Male $(N=390)$} \\
\hline & \multicolumn{2}{|c|}{ Eq-5d index } & \multicolumn{2}{|l|}{ VAS } & \multirow{2}{*}{$\begin{array}{l}\text { Eq-5d index } \\
\text { Mean/SD }\end{array}$} & \multirow{2}{*}{$\begin{array}{l}\text { VAS } \\
\text { Mean/SD }\end{array}$} & \multirow{2}{*}{$\begin{array}{l}\text { Eq-5d index } \\
\text { Mean/SD }\end{array}$} & \multirow{2}{*}{$\begin{array}{l}\text { VAS } \\
\text { Mean/SD }\end{array}$} \\
\hline & Mean/SD & t-test ${ }^{a}$ & Mean/SD & t-test ${ }^{a}$ & & & & \\
\hline \multicolumn{9}{|l|}{ Socioeconomic Status } \\
\hline Low & $0.67 / 0.20$ & $7.27^{* * *}$ & $62.41 / 20.08$ & $7.28^{* * *}$ & $0.66 / 0.19$ & $62.16 / 19.32$ & $0.67 / 0.21$ & $62.77 / 21.20$ \\
\hline High & $0.77 / 0.16$ & & $72.94 / 18.18$ & & $0.76 / 0.16$ & $72.31 / 17.89$ & $0.77 / 0.17$ & $73.58 / 18.46$ \\
\hline \multicolumn{9}{|l|}{ Educational Level } \\
\hline Illiteracy & $0.68 / 0.18$ & $12.97^{* * *}$ & $63.57 / 19.34$ & $13.43^{* * *}$ & $0.68 / 0.18$ & $63.51 / 18.89$ & $0.68 / 0.19$ & 63.66/19.99 \\
\hline Elementary and above & $0.83 / 0.12$ & & $80.61 / 13.83$ & & $0.84 / 0.10$ & $81.84 / 11.41$ & $0.82 / 0.14$ & $79.71 / 15.33$ \\
\hline \multicolumn{9}{|l|}{ Poor housing conditions } \\
\hline Yes & $0.71 / 0.19$ & $6.16^{* * *}$ & $66.92 / 19.77$ & $6.38^{* * *}$ & $0.71 / 0.18$ & $66.41 / 19.44$ & $0.72 / 0.19$ & $67.53 / 20.18$ \\
\hline No & $0.79 / 0.15$ & & $75.86 / 16.95$ & & $0.78 / 0.15$ & $75.03 / 16.31$ & $0.80 / 0.15$ & $76.61 / 17.53$ \\
\hline \multicolumn{9}{|l|}{ Income-based group } \\
\hline Quintile1 (poor) & $0.72 / 0.19$ & $3.07^{* *}$ & $67.80 / 19.74$ & $3.11^{* *}$ & $0.71 / 0.18$ & $67.10 / 19.04$ & $0.73 / 0.19$ & $68.61 / 20.53$ \\
\hline Quintile2 (rich) & $0.76 / 0.17$ & & $72.00 / 18.71$ & & $0.75 / 0.17$ & 71.03/18.69 & $0.76 / 0.17$ & $73.00 / 18.72$ \\
\hline
\end{tabular}

${ }^{*} P<0.05,{ }^{* *} P<0.01,{ }^{* * *} P<0.001$

${ }^{a}$ The $t$ test was employed to examine whether there was a significant difference in the mean between the two groups of a variable

0.027 for females, and 0.021 and 0.025 for males, respectively.

Table 6 describes the CI decomposition of the health inequality in the total sample and gender subgroups. For the total sample, SES contributed 45.50 and $41.39 \%$ to health inequality for the Eq-5d index and VAS, respectively. For females, the contribution of SES to health inequality was $44.29 \%$ for the Eq-5d index and 39.39\% for VAS. Similarly, for males, 46.37 and $43.27 \%$ of the health inequality for the Eq-5d index and VAS was attributable to SES, respectively.

\section{Discussion}

This study revealed the health status and health inequality of residents in the agricultural and pastoral areas of Tibet based on HRQoL, analyzed the relationship between SES and HRQoL among Tibetans in APA, and estimated the contribution of SES on the health inequality of the population.

The results revealed the relatively low HRQoL among Tibetans in APA in China. In western China, rural residents in Shaanxi province scored an Eq-5d index of 0.95 [42], higher than HRQoL of the participants of this study in Tibet. Compared to the other population in Tibet, Tibetans in APA also had lower HRQoL. A survey of medical staff in Tibet showed that the average score of the Eq-5d index was 0.79, and VAS was 75.02 [43], which is higher than the HRQoL in this study.

The findings of this study showed that low SES was significantly associated with low HRQoL. Consistent with this study, a recent study of the general population

Table 3 Factors influenced Eq-5d index (Multiple linear regression model)

\begin{tabular}{|c|c|c|c|c|c|c|}
\hline \multirow[t]{2}{*}{ Variables } & \multicolumn{2}{|c|}{ Total sample $(N=816)$} & \multicolumn{2}{|c|}{ Female $(N=426)$} & \multicolumn{2}{|c|}{ Male $(N=390)$} \\
\hline & Coef. $\left(\beta_{\mathbf{i}}\right)$ & 95\% Conf. interval & Coef. $\left(\beta_{\mathbf{i}}\right)$ & 95\% Conf. interval & Coef. $\left(\beta_{\mathrm{i}}\right)$ & $95 \%$ Conf. interval \\
\hline Socioeconomic Status (Ref: low) & $0.05^{* *}$ & $(0.02,0.08)$ & $0.05^{*}$ & $(0.006,0.09)$ & $0.05^{*}$ & $(0.004,0.10)$ \\
\hline Age & $-0.004^{* * *}$ & $(-0.005,-0.004)$ & $-0.004^{* * *}$ & $(-0.005,-0.003)$ & $-0.005^{* * *}$ & $(-0.006,-0.004)$ \\
\hline Gender (Ref: female) & 0.008 & $(-0.01,0.03)$ & & & & \\
\hline Marital status (Ref: unmarried) & $0.05^{* * *}$ & $(0.02,0.07)$ & 0.03 & $(-0.006,0.06)$ & $0.07^{* * *}$ & $(0.04,0.11)$ \\
\hline Smoking (Ref: no) & $0.04^{* *}$ & $(0.02,0.07)$ & $0.03^{*}$ & $(0.0005,0.07)$ & $0.05^{* *}$ & $(0.02,0.08)$ \\
\hline Brush teeth every day (Ref: no) & 0.009 & $(-0.01,0.03)$ & 0.02 & $(-0.02,0.05)$ & 0.005 & $(-0.03,0.04)$ \\
\hline Medical examination (Ref: no) & 0.02 & $(-0.003,0.05)$ & 0.03 & $(-0.01,0.06)$ & 0.02 & $(-0.02,0.06)$ \\
\hline Distance (Ref: within three kilometers) & -0.004 & $(-0.03,0.02)$ & -0.0002 & $(-0.03,0.03)$ & -0.01 & $(-0.04,0.02)$ \\
\hline Chronic disease (Ref: without) & -0.02 & $(-0.05,0.004)$ & -0.01 & $(-0.05,0.03)$ & -0.03 & $(-0.07,0.003)$ \\
\hline Constant & $0.81^{* * *}$ & $(0.77,0.85)$ & $0.81^{* * *}$ & $(0.76,0.86)$ & $0.82^{* * *}$ & $(0.76,0.88)$ \\
\hline
\end{tabular}

${ }^{*} P<0.05,{ }^{* *} P<0.01,{ }^{* * * P}<0.001$ 
Table 4 Factors influenced VAS (Multiple linear regression model)

\begin{tabular}{|c|c|c|c|c|c|c|}
\hline \multirow[t]{2}{*}{ Variables } & \multicolumn{2}{|c|}{ Total sample $(\mathrm{N}=816)$} & \multicolumn{2}{|c|}{ Female $(N=426)$} & \multicolumn{2}{|c|}{ Male $(\mathrm{N}=390)$} \\
\hline & Coef. $\left(\beta_{i}\right)$ & 95\% Conf. interval & Coef. $\left(\beta_{i}\right)$ & 95\% Conf. interval & Coef. $\left(\beta_{\mathrm{i}}\right)$ & 95\% Conf. interval \\
\hline Socioeconomic Status (Ref: low) & $5.01^{* *}$ & $(1.88,8.15)$ & $4.64^{*}$ & $(0.42,8.86)$ & $5.36^{*}$ & $(0.60,10.13)$ \\
\hline Age & $-0.47^{* * *}$ & $(-0.54,-0.40)$ & $-0.43^{* * *}$ & $(-0.53,-0.33)$ & $-0.53^{* * *}$ & $(-0.63,-0.43)$ \\
\hline Gender (Ref: female) & 0.85 & $(-1.48,3.17)$ & & & & \\
\hline Marital status (Ref: unmarried) & $5.24^{* * *}$ & $(2.81,7.66)$ & 2.73 & $(-0.63,6.08)$ & $8.50^{* * *}$ & $(4.93,12.07)$ \\
\hline Smoking (Ref: no) & $5.00^{* * *}$ & $(2.45,7.55)$ & $4.28^{*}$ & $(0.73,7.83)$ & $5.76^{* *}$ & $(2.10,9.42)$ \\
\hline Brush teeth every day (Ref: no) & 0.77 & $(-1.79,3.32)$ & 1.61 & $(-1.91,5.13)$ & 0.32 & $(-3.44,4.07)$ \\
\hline Medical examination (Ref: no) & $3.78^{* *}$ & $(0.97,6.58)$ & $4.00^{*}$ & $(0.09,7.91)$ & 3.29 & $(-0.72,7.30)$ \\
\hline Distance (Ref: within three kilometers) & -0.19 & $(-2.58,2.20)$ & -0.08 & $(-3.32,3.17)$ & -0.68 & $(-4.21,2.86)$ \\
\hline Chronic disease (Ref: without) & -2.48 & $(-5.29,0.32)$ & -1.08 & $(-4.89,2.74)$ & -4.04 & $(-8.23,0.15)$ \\
\hline Constant & $77.33^{* * *}$ & $(73.21,81.46)$ & $77.28^{* * *}$ & $(71.66,82.89)$ & $78.69^{* * *}$ & $(72.62,84.76)$ \\
\hline
\end{tabular}

${ }^{*} P<0.05,{ }^{*} P<0.01,{ }^{* * * P}<0.001$

revealed that high SES is positively associated with the quality of life of Chinese people [44]. Similar results were found in studies of ethnic minorities in China; a study of Dai residents in Yunnan province showed that the higher their socioeconomic status, the higher their life quality score [45]. Another survey among the residents of the Hui ethnic minority group showed that socioeconomic status affects health level, and the influence was more significant in rural areas than in urban areas [46]. The conclusions drawn in this study also corroborate the findings of other countries $[47,48]$. SES determines people's living and working environment and determines accessibility to a variety of health products and services [34]. Furthermore, SES affects people's psychological state and cognition of the world around them [49, 50]. These physical and psychological factors, in turn, influence how people behave and the probability of exposure to various risk factors that affect their health [51].

The results revealed that there was pro-rich inequality in the health of Tibetans in APA, but the degree of inequality is relatively low. Similar conclusions have been drawn from previous studies in China [52], and in urban and rural areas in this country [53, 54]. Studies targeting specific groups, such as the elderly and rural residents in western China, also revealed pro-rich health inequality $[55,56]$.

SES contributed to inequality in over $40 \%$ of all factors considered in this study. Most studies have reached consistent conclusions on the contribution of SES to health inequality. Income is the main factor affecting health inequality [57]. For both urban and rural residents, income was the most significant contributing factor to health inequality $[53,54,58]$ and widening income inequality increased healthy inequality $[15,59,60]$. Other socioeconomic variables such as region, education level, and occupation are also major factors affecting health inequality [61, 62]. Studies of specific populations, such as the elderly and migrant populations, have shown similar results $[63,64]$. The impact of SES on health inequality is achieved through several indicators, among which education, occupation, income, housing conditions, household registration, and other relevant demographic factors all have impacts on health inequality. In this study, education, income, and housing conditions were included in the measurement of SES differences because of the characteristics of the participants. Tibetans in APA are generally poorly educated and a high proportion are illiterate. Schooling has obvious influence on health cognition and health literacy [50,65], as well as health-related lifestyle [66-68]. This study indicated that the relationship between SES and HRQoL among Tibetans deserves strong attention. The implementation of some strategies that help to improve SES can also improve HRQoL of Tibetans in APA to a large extent, such as strengthening the elementary education, the publicity and education regarding public health, and conducting extensive health education and healthy lifestyle guidance. Income and housing conditions also reflected the SES situation of Tibetans in APA. The agricultural and pastoral areas in Tibet are areas with high concentrations of

Table 5 Concentration index of Eq-5d index and VAS

\begin{tabular}{|c|c|c|c|c|c|c|}
\hline \multirow[t]{2}{*}{ Variables } & \multicolumn{2}{|l|}{ Total } & \multicolumn{2}{|c|}{ Female } & \multicolumn{2}{|l|}{ Male } \\
\hline & $\mathrm{Cl}$ & $95 \% \mathrm{Cl}$ & $\mathrm{Cl}$ & $95 \% \mathrm{Cl}$ & $\mathrm{Cl}$ & $95 \% \mathrm{Cl}$ \\
\hline Eq-5d index & 0.022 & $(0.012,0.032)$ & 0.023 & $(0.010,0.036)$ & 0.021 & $(0.006,0.035)$ \\
\hline VAS & 0.026 & $(0.015,0.037)$ & 0.027 & $(0.012,0.042)$ & 0.025 & $(0.009,0.041)$ \\
\hline
\end{tabular}


Table 6 Contributions of Socioeconomic Status and other factors for health inequality (\%)

\begin{tabular}{|c|c|c|c|c|c|c|}
\hline & \multicolumn{3}{|c|}{ Eq-5d index } & \multicolumn{3}{|l|}{ VAS } \\
\hline & Total & Female & Male & Total & Female & Male \\
\hline Socioeconomic Status & 45.50 & 44.29 & 46.37 & 41.39 & 39.34 & 43.27 \\
\hline Other factors & 31.44 & 25.86 & 38.12 & 34.64 & 29.02 & 40.90 \\
\hline Total & 76.94 & 70.15 & 84.48 & 76.03 & 68.36 & 84.17 \\
\hline
\end{tabular}

poverty [2]. Our study found that $40.07 \%$ of the subjects lived below the international poverty line. To help poor families in agricultural and pastoral areas, the government should actively implement supportive measures. Effective poverty alleviation policies aimed at local residents would be helpful to improve the quality of life and overall health of Tibetans in APA. Strengthening public infrastructure such as reconstructing water supply and lavatory would also be helpful to decrease the health risks the local residents are faced with.

Our study has some limitations. First, the crosssectional data used in this study can only explain the correlation between SES and HRQoL, but fail to examine the causal relationship. The inference of the causal relationship between SES and HRQoL among Tibetans in APA needs to be further verified. Second, due to the difficulty of investigation and the availability of the data, the sample size is relatively small. Also since the sample is not strictly proportional to the population of different counties and villages, the sample representation may be relatively weak, which may result in selection bias. Third, in some studies, subjective social status has shown a better correlation with health than objective social status. A longitudinal study of Britain also showed that subjective social status was a better predictor of health than income and education [69]. The combination of some subjective and objective indicators should be considered to measure socioeconomic status in future studies.

\section{Conclusions}

This study revealed a slight pro-rich inequality in the health of Tibetans in agricultural and pastoral areas in China. SES was found to be the main contributing factor to health inequality, and low SES is associated with relatively poor quality of life among Tibetans in APA. This particular group of Tibetans, especially poor people without formal education, deserves more attention. Targeted policies and strategies need to be strengthened, including education improvement and poverty alleviation.

\section{Abbreviations}

SES: Socioeconomic status; HRQoL: Health-related quality of life APA: Agricultural and pastoral areas; Cl: Concentration Index; VAS: Visual Analog Scale; TTO: Time-Trade Off

Acknowledgements

Not applicable.

\section{Authors' contributions}

$\mathrm{HY}$ and $\mathrm{HG}$ designed the study and participated in the data analysis. JANM and XXP led the data analysis and wrote the manuscript. JHG and NC participated in the data analysis. JHG and XLL made important contributions to the revision of the manuscript. XLL and YK participated in the revision of the manuscript and the improvement of English writing. All authors have read and approved the final manuscript.

\section{Funding}

This study was founded by the National Natural Science Foundation of China, grant number 71573118 . The funders played no role in the study design, data collection and analysis, the interpretation of data, and in the writing of the manuscript.

\section{Availability of data and materials}

Data are available upon reasonable request from the corresponding author or Center for health policy and management studies, Nanjing University. Email:youhua98@163.com

\section{Ethics approval and consent to participate}

Ethical approval was obtained from the Medical Faculty Ethics Committee of Nanjing Medical University (file number 316) and written informed consent from every participant was obtained before the investigation.

\section{Consent for publication}

No applicable.

\section{Competing interests}

The authors declare that they have no competing interests.

\section{Author details}

${ }^{1}$ Center for Health Policy and Management Studies, Nanjing University, Nanjing, China. ${ }^{2}$ Department of Social Medicine and Health Education, School of Public Health, Nanjing Medical University, Nanjing, China. ${ }^{3}$ Nanjing Foreign Language School, Nanjing, China. ${ }^{4}$ Department of Otolaryngology, The First Affiliated Hospital of Nanjing Medical University, Nanjing, China.

Received: 8 July 2019 Accepted: 27 April 2020

Published online: 06 May 2020

\section{References}

1. Zhou Z. Research on the village public service system innovation of agricultural and pastoral areas in tibet--from the perspective of integrated anti-poverty development. J Ethnol. 2012;3(01):34-43. (in Chinese).

2. Ling Z. The relationship between public service supply and the lessening of poverty at in grass-root units in tibetan agricultural and pastoral areas. Manag World. 2004;4:41-50 +155-156. (in Chinese).

3. Ling Z. The health risks and services for the population in farming and stockbreeding areas. Manag World. 2005;2:41-56 +171-172. (in Chinese).

4. Adler NE, Ostrove JM. Socioeconomic status and health: what we know and what we don't. Ann N Y Acad Sci. 1999;896(1):3-15.

5. Kaplan GA, Keil JE. Socioeconomic factors and cardiovascular disease: a review of the literature. Circulation. 1993;88(4):1973-98.

6. Williams DR. Socioeconomic differentials in health: a review and redirection. Soc Psychol Q. 1990;53(2):81-99.

7. Marmot M, Wilkinson R. Social determinants of health. Oxford: OUP; 2005.

8. Winkleby MA, Jatulis DE, Frank E, Fortmann SP. Socioeconomic status and health: how education, income, and occupation contribute to risk factors for cardiovascular disease. Am J Public Health. 1992;82(6):816-20.

9. Winkleby MA, Fortmann SP, Barrett DC. Social class disparities in risk factors for disease: eight-year prevalence patterns by level of education. Prev Med. 1990;19(1):1-12.

10. Ross CE, Mirowsky J. Why education is the key to socioeconomic differentials in health. Handbook Med Soc. 2010;6:33-51.

11. Bartley M. Health inequality: an introduction to concepts, theories and methods. Cambridge: Polity Press; 2016

12. Smith GD, Bartley M, Blane D. The black report on socioeconomic inequalities in health 10 years on. BMJ. 1990;301 (6748):373.

13. Mackenbach JP, Stirbu I, Roskam A-JR, Schaap MM, Menvielle G, Leinsalu M, Kunst AE. Socioeconomic inequalities in health in 22 European countries. N Engl J Med. 2008;358(23):2468-81. 
14. Marmot M, Friel S, Bell R, Houweling TA, Taylor S. Health CoSDo: closing the gap in a generation: health equity through action on the social determinants of health. Lancet. 2008;372(9650):1661-9.

15. Pickett KE, Wilkinson RG. Income inequality and health: a causal review. Soc Sci Med. 2015;128:316-26.

16. Kawachi I, Kennedy BP. Socioeconomic determinants of health: health and social cohesion: why care about income inequality? BMJ. 1997;314(7086):1037.

17. Singh L, Goel R, Rai RK, Singh PK. Socioeconomic inequality in functional deficiencies and chronic diseases among older Indian adults: a sex-stratified cross-sectional decomposition analysis. BMJ Open. 2019;9(2):e022787.

18. Djärv T, Wikman A, Johar A, Lagergren P. Poor health-related quality of life in the Swedish general population: the association with disease and lifestyle factors. Scand J Public Health. 2013;41(7):744-53.

19. Razzaque A, Nahar L, Akter Khanam M, Kim Streatfield P. Socio-demographic differentials of adult health indicators in Matlab, Bangladesh: self-rated health, health state, quality of life and disability level. Glob Health Action. 2010:3(1):4618

20. Mielck A, Reitmeir P, Vogelmann M, Leidl R. Impact of educational level on health-related quality of life ( $\mathrm{HRQL})$ : results from Germany based on the EuroQol 5D (EQ-5D). Eur J Public Health. 2012;23(1):45-9.

21. Lubetkin El, Jia H, Franks P, Gold MR. Relationship among sociodemographic factors, clinical conditions, and health-related quality of life: examining the EQ-5D in the US general population. Qual Life Res. 2005; 14(10):2187-96.

22. Mielck A, Vogelmann M, Leidl R. Health-related quality of life and socioeconomic status: inequalities among adults with a chronic disease. Health Qual Life Outcomes. 2014;12(1):58.

23. Luo N, Chew L-H, Fong K-Y, Koh D-R, Ng S-C, Yoon K-H, Vasoo S, Li S-C, Thumboo J. Do English and Chinese EQ-5D versions demonstrate measurement equivalence? An exploratory study. Health Qual Life Outcomes. 2003;1(1):7.

24. Wang H, Kindig DA, Mullahy J. Variation in Chinese population health related quality of life: results from a EuroQol study in Beijing, China. Qual Life Res. 2005;14(1):119-32.

25. Wang H-M, Patrick DL, Edwards TC, Skalicky AM, Zeng H-Y, Gu W-W. Validation of the EQ-5D in a general population sample in urban China. Qual Life Res. 2012;21(1):155-60.

26. Tsuchiya A, Ikeda S, Ikegami N, Nishimura S, Sakai I, Fukuda T, Hamashima C, Hisashige A, Tamura M. Estimating an EQ-5D population value set: the case of Japan. Health Econ. 2002;11(4):341-53.

27. Szende A, Janssen B, Cabases J. Self-reported population health: an international perspective based on EQ-5D. Dordrecht: Springer; 2014.

28. Feinstein JS. The relationship between socioeconomic status and health: a review of the literature. Milbank Q. 1993;71(2):279-322.

29. Duncan GJ, Daly MC, McDonough P, Williams DR. Optimal indicators of socioeconomic status for health research. Am J Public Health. 2002;92(7):1151-7.

30. Grundy E, Holt G. The socioeconomic status of older adults: how should we measure it in studies of health inequalities? J Epidemiol Community Health. 2001:55(12):895-904.

31. WHO. Distribution of health payments and catastrophic expenditures methodology; 2015. Available from URL [https://apps.who.int/iris/bitstream/ handle/10665/69030/EIP_HSF_DP_05.2.pdf].

32. Gu H, Kou Y, Yan Z, Ding Y, Shieh J, Sun J, Cui N, Wang Q, You H. Income related inequality and influencing factors: a study for the incidence of catastrophic health expenditure in rural China. BMC Public Health. 2017;17(1):727.

33. Gu H, Kou Y, You H, Xu X, Yang N, Liu J, Liu X, Gu J, Li X. Measurement and decomposition of income-related inequality in self-rated health among the elderly in China. Int J Equity Health. 2019;18(1):4.

34. Jiang $Y$, Hesser JE. Associations between health-related quality of life and demographics and health risks. Results from Rhode Island's 2002 behavioral risk factor survey. Health Qual life Outcomes. 2006;4(1):14.

35. Huguet N, Kaplan MS, Feeny D. Socioeconomic status and health-related quality of life among elderly people: results from the joint Canada/United States survey of health. Soc Sci Med. 2008;66(4):803-10.

36. Saarni SI, Härkänen T, Sintonen H, Suvisaari J, Koskinen S, Aromaa A, Lönnqvist J. The impact of 29 chronic conditions on health-related quality of life: a general population survey in Finland using 15D and EQ-5D. Qual Life Res. 2006;15(8):1403-14.

37. Konings $P$, Harper S, Lynch J, Hosseinpoor AR, Berkvens D, Lorant V, Geckova A, Speybroeck N. Analysis of socioeconomic health inequalities using the concentration index. Int J Public Health. 2010;55(1):71-4.
38. Morasae EK, Forouzan AS, Majdzadeh R, Asadi-Lari M, Noorbala AA, Hosseinpoor AR. Understanding determinants of socioeconomic inequality in mental health in Iran's capital, Tehran: a concentration index decomposition approach. Int J Equity Health. 2012;11(1):18.

39. Wagstaff A, Van Doorslaer E, Watanabe N. On decomposing the causes of health sector inequalities with an application to malnutrition inequalities in Vietnam. J Econ. 2003;112(1):207-23.

40. Francisco F, Dean Mitchell J, Espen Beer P: The international poverty line has just been raised to $\$ 1.90$ a day, but global poverty is basically unchanged. How is that even possible? Available from URL: [https://blogs. worldbank.org/developmenttalk/international-poverty-line-has-just-beenraised-190-day-global-poverty-basically-unchanged-how-even].

41. Francisco FH, Shaohua C, Andrew D, Yuri D, Nada H, Dean J, Ambar N, Espen Beer P, Ana R, Prem S, et al. A global count of the extreme poor in 2012 data issues, methodology and initial results. Washington, D.C: The World Bank; 2015.

42. Zhongliang Z, Zhiying Z, Dan L, Dan W, Chao S, Chi S, Yu F, Jianmin G, Gang C. Analyzing the health-related quality of life of urban and rural residents in Shaanxi: estimation based on the EQ-5D value sets. Chin Health Econ. 2015;34(02):13-6. (in Chinese).

43. Deji Z, Dawa Z, Youwen L, Ji D, Yonghua H. Study on the quality of life of Tibetan health workers in Shannan District of the Tibet autonomous region. Modern Prev Med. 2016;43(10):1766-9. (in Chinese).

44. Haijing G, Guo-en L. Comparison analysis on health related quality of life among urban and rural residents in 4 cities of China. Chin Health Econ. 2015;34(02):5-12. (in Chinese).

45. Yongli Z. Analysis of Different social-economic status on the prevalence of hypertension and Its' impact on quality of life among Dai ethnic minority in Yunnan province. KunMing, China: Kunming Medical University; 2017. (in Chinese).

46. Feng Y, Fei T, Yanrong K. On socioeconomic and health status of Hui nationality residents in China--an empirical analysis based on data from CGSS. J Hui Muslim Minor Stud. 2018;28(01):51-8. (in Chinese).

47. Braveman PA, Cubbin C, Egerter S, Williams DR, Pamuk E. Socioeconomic disparities in health in the United States: what the patterns tell us. Am J Public Health. 2010;100(S1):S186-96.

48. Williams DR, Mohammed SA, Leavell J, Collins C. Race, socioeconomic status, and health: complexities, ongoing challenges, and research opportunities. Ann N Y Acad Sci. 2010;1186(1):69-101.

49. Matthews KA, Gallo LC. Psychological perspectives on pathways linking socioeconomic status and physical health. Annu Rev Psychol. 2011;62:501-30.

50. Christopher Auld M, Sidhu N. Schooling, cognitive ability and health. Health Econ. 2005;14(10):1019-34.

51. Shuyi $X$, Ningning W. Economic status, subjective social status and self-rated health. Stat Res. 2015;32(03):62-8. (in Chinese).

52. Ying C, Jiangmei $Q$, Jingxia T, Yang Z, Lifang Z, Yanchun Z. Income-related health inequality and decomposition. Chin Health Econ. 2016;35(04):71-3. (in Chinese).

53. Jing Z. Income-related health inequality in China and its decomposition-an empirical analysis based on CGSS2008 data. J Guizhou Univ Fin Econ. 2013;03:52-7. (in Chinese).

54. Rugang $L$, Jingjing $L$, Jian $W$. Analyzing the health equity of rural residents in China and its decomposition. Chin Health Serv Manag. 2016;33(08):6114. (in Chinese).

55. Yanli L, Lexiang $T$, Ju-e $Y$, Jianmin $G$. Health inequality of rural residents and its decomposition. Stat Decision. 2015;20:116-8. (in Chinese).

56. Tianxing $W$, Junjiang $H$. Non-equilibrium analysis of urban and rural elderly in China from the perspective of medical and pension combined. Dongyue Tribune. 2018;39(07):169-77. (in Chinese).

57. Liu Y, Hsiao WC, Eggleston K. Equity in health and health care: the Chinese experience. Soc Sci Med. 1999;49(10):1349-56.

58. Yang W, Kanavos $P$. The less healthy urban population: income-related health inequality in China. BMC Public Health. 2012;12(1):804.

59. Lynch JW, Smith GD, Kaplan GA, House JS. Income inequality and mortality: importance to health of individual income, psychosocial environment, or material conditions. BMJ. 2000;320(7243):1200-4

60. Baeten S, Van Ourti T, Van Doorslaer E. Rising inequalities in income and health in China: who is left behind? J Health Econ. 2013;32(6):1214-29.

61. Veiga PA. Income-related health inequality in Portugal: working paper; 2005.

62. Doorslaer EV, Koolman X. Explaining the differences in income-related health inequalities across European countries. Health Econ. 2004;13(7): 609-28. 
63. Tao T, Qian Z, Hongrui L. Decomposition of health inequalities among elderly people in rural China: an empirical research based on the survey of eastern, central and Western China. South China Popul. 2015;30(03):57-68. (in Chinese).

64. Qinchi W. Measurement and decomposition of health inequality among floating population in China. Chin Health Econ. 2016;35(01):69-72. (in (hinese).

65. Van der Heide I, Wang J, Droomers M, Spreeuwenberg P, Rademakers J, Uiters $\mathrm{E}$. The relationship between health, education, and health literacy: results from the Dutch Adult Literacy and Life Skills Survey. J Health Commun. 2013;18(sup1):172-84.

66. Cowell AJ. The relationship between education and health behavior: some empirical evidence. Health Econ. 2006;15(2):125-46.

67. Huerta MC, Borgonovi F. Education, alcohol use and abuse among young adults in Britain. Soc Sci Med. 2010;71(1):143-51.

68. Pampel FC, Denney JT. Cross-national sources of health inequality: education and tobacco use in the world health survey. Demography. 2011; 48(2):653-74.

69. Singh-Manoux A, Marmot MG, Adler NE. Does subjective social status predict health and change in health status better than objective status? Psychosom Med. 2005;67(6):855-61.

\section{Publisher's Note}

Springer Nature remains neutral with regard to jurisdictional claims in published maps and institutional affiliations.

Ready to submit your research? Choose BMC and benefit from:

- fast, convenient online submission

- thorough peer review by experienced researchers in your field

- rapid publication on acceptance

- support for research data, including large and complex data types

- gold Open Access which fosters wider collaboration and increased citations

- maximum visibility for your research: over $100 \mathrm{M}$ website views per year

At $\mathrm{BMC}$, research is always in progress.

Learn more biomedcentral.com/submissions 